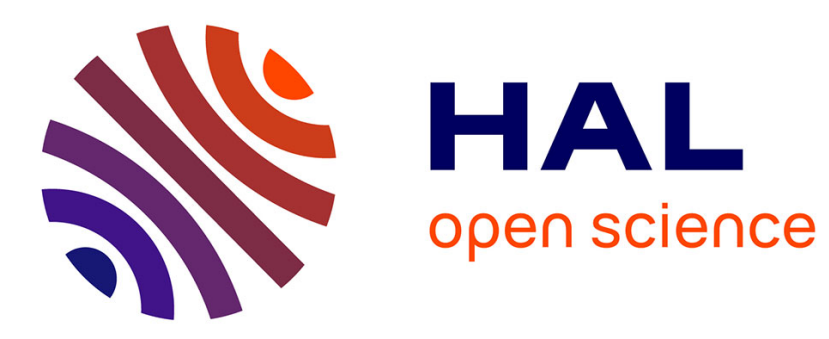

\title{
On the efficiency of shock magnetization processes
}

\author{
J. Gattacceca, L. Berthe, M. Boustie, F. Vadeboin, P. Rochette, T. de
}

Resseguier

\section{To cite this version:}

J. Gattacceca, L. Berthe, M. Boustie, F. Vadeboin, P. Rochette, et al.. On the efficiency of shock magnetization processes. Physics of the Earth and Planetary Interiors, 2008, 166 (1-2), pp.1. 10.1016/j.pepi.2007.09.005 . hal-00532128

\section{HAL Id: hal-00532128 \\ https://hal.science/hal-00532128}

Submitted on 4 Nov 2010

HAL is a multi-disciplinary open access archive for the deposit and dissemination of scientific research documents, whether they are published or not. The documents may come from teaching and research institutions in France or abroad, or from public or private research centers.
L'archive ouverte pluridisciplinaire HAL, est destinée au dépôt et à la diffusion de documents scientifiques de niveau recherche, publiés ou non, émanant des établissements d'enseignement et de recherche français ou étrangers, des laboratoires publics ou privés. 


\section{Accepted Manuscript}

Title: On the efficiency of shock magnetization processes

Authors: J. Gattacceca, L. Berthe, M. Boustie, F. Vadeboin, P. Rochette, T. De Resseguier

PII: $\quad$ S0031-9201(07)00205-1

DOI: $\quad$ doi:10.1016/j.pepi.2007.09.005

Reference: $\quad$ PEPI 4871

To appear in: $\quad$ Physics of the Earth and Planetary Interiors

Received date: $\quad$ 6-7-2007

Revised date: $\quad$ 14-9-2007

Accepted date: $\quad$ 25-9-2007

Please cite this article as: Gattacceca, J., Berthe, L., Boustie, M., Vadeboin, F., Rochette, P., De Resseguier, T., On the efficiency of shock magnetization processes, Physics of the Earth and Planetary Interiors (2007), doi:10.1016/j.pepi.2007.09.005

This is a PDF file of an unedited manuscript that has been accepted for publication. As a service to our customers we are providing this early version of the manuscript. The manuscript will undergo copyediting, typesetting, and review of the resulting proof before it is published in its final form. Please note that during the production process errors may be discovered which could affect the content, and all legal disclaimers that apply to the journal pertain. 


\title{
On the efficiency of shock magnetization processes
}

\author{
J. Gattacceca ${ }^{1}$, L. Berthe ${ }^{2}$, M. Boustie ${ }^{3}$, F. Vadeboin ${ }^{1}$, P. Rochette ${ }^{1}$, T. De Resseguier ${ }^{3}$ \\ 1: CEREGE (CNRS / Université Aix-Marseille), BP80, 13545 Aix-en-Provence Cedex 4, France \\ 2: LALP, UPR CNRS 1578, 16 bis avenue du Prieuré de la Côte d'Or, 94114 Arcueil Cedex, France \\ 3: LCD, UPR CNRS 9028, ENSMA, 1 avenue Clément Ader, BP 40109, 86961 Futuroscope Cedex, France
}

\begin{abstract}
The acquisition of remanent magnetization caused by hypervelocity impacts may be a major contribution to the remanent magnetization of planetary surfaces and meteorites. In this paper, we investigate the properties of shock remanent magnetization (SRM) and in particular the relative efficiency of this phenomenon with respect to thermoremanent magnetization (TRM), a parameter of interest for the understanding of the magnetic signatures of impact basins on extraterrestrial bodies. We imparted shock remanent magnetization on basalt and microdiorite samples using laser shock in controlled magnetic field. Shock modeling indicates a pressure range of 0.6-1.5 GPa for our experiments. The results confirm that the SRM is parallel to the ambient magnetic field. SRM increases inearly with the ambient field in the $1 \mu \mathrm{T}-2500 \mu \mathrm{T}$ range. The intensity of SRM is independent of the angle between the shock direction and the direction of the ambient field. The coercivity spectrum of SRM is shifted towards lower values compared to the coercivity spectra of TRM and isothermal remanent magnetization. For the two studied lithologies, the efficiency of SRM vs TRM acquisition is $\geq 17 \%$ for the basalt and is $36 \%$ for the microdiorite. This efficiency depends on the magnetic mineralogy and increases with decreasing coercivity. The rather high efficiency values that we obtained show that a significant remanent magnetization can be acquired by the crust during an hypervelocity impact on a planetary surface in the presence of an ambient field.
\end{abstract}

\section{Introduction}

The effect of shock waves on the remanent magnetization of rocks has implications for the understanding of the magnetic anomalies associated with impact basins on Mars (Hood et al., 2003), the Moon (Halekas et al., 2003) or Earth (Pilkington and Grieve, 1992), and also for the interpretation of the paleomagnetic signal of meteorites and lunar rocks that have all been shocked to a variable degree.

Leaving aside the possible thermoremanent magnetization (TRM) carried by the central volume of rock that was heated above blocking temperatures during the impact (if it is preserved), the magnetic anomalies observed above impact basins are mainly attributed to the 
much larger volume of surrounding rocks that were affected by relatively low to moderate shock pressures (typically $>1 \mathrm{GPa}$ ). The interpretation of this magnetic signature in terms of magnetic mineralogy of the crust or in terms of presence/absence of a magnetic field (global field created by a dynamo or transient field created by the impact) is closely related to the efficiency of shock remanent magnetization (SRM) acquisition. Yet this efficiency has never been determined precisely.

Since the 1970's, a number of studies have dealt with the demagnetization by shock waves of natural (e.g. Cisowski and Fuller, 1978; Pohl et al., 1975; Hargraves and Perkins, 1969; Gattacceca et al., 2007) or artificial (e.g. Nagata, 1971; Gattacceca et al., 2006, Louzada et al., 2006) remanent magnetization. Much less has been done on the acquisition of remanent magnetization upon shock. Only few papers address this particular issue: Nagata (1971) who actually named this type of magnetization "shock remanent magnetization" (SRM), Pohl et al. (1975) and Nagata et al. (1983). In these works, demagnetized rock samples were submitted to shock in a controlled magnetic field. Although the work by Nagata (1971) was pioneering and set the basis of the understanding of SRM, the maximum shock pressures were in the $45 \mathrm{MPa}$ range, which is about two orders of magnitude lower than the pressures experienced during natural hypervelocity impacts (several GPa). Moreover, no information was provided about the magnetic properties of the target rocks, which are necessary to fully understand the phenomena. Pohl et al. (1975) conducted experiments on basalt with shock pressures up to $1 \mathrm{GPa}$ but did not discuss the efficiency of the SRM acquisition. In order to determine the efficiency of SRM acquisition, we conducted shock experiments with a pulsed laser in controlled magnetic field on previously demagnetized samples.

\section{Description of the target rocks}

Our shock experiments were conducted mostly on a Pleistocene basalt from Chanteuges (Haute-Loire, France) and to a lesser extent on a microdiorite from the Esterel range (France). The basalt is an alkaline basalt containing less than $5 \%$ of phenocrystals (mainly olivine and clinopyroxene in equal proportion and up to $1.5 \mathrm{~mm}$ in size, and some rare opaque minerals). The matrix is finely crystallized with an intergranular texture. It contains clinopyroxene (about 20\%), plagioclase, olivine and opaque minerals. The microdiorite has a microgranular matrix composed of plagioclase and quartz. The phenocrystals in the microdiorite consist in large zoned automorphic plagioclase crystals, green hornblende crystals, and a few large opaque crystals. 
The magnetic properties of the basalt and the microdiorite are synthetized in Table 1 that also provides some petrophysical parameters of interest for shock wave propagation (density, sound speed, porosity). Based on experimental work and numerical simulations, Berthe et al. (2007) describes the mechanical behaviour of this particular basalt under short (ns) and moderate-pressure ( $\sim \mathrm{GPa})$ shock wave comparable to pressure loadings used in the present paper. The mechanical properties and modeling parameter obtained by Berthe et al. (2007) are given in Table 2 .

Hysteresis properties and thermomagnetic analyses indicate that titanomagnetite is the main magnetic mineral in the basalt. The thermomagnetic curves display two Curie temperatures at $60^{\circ} \mathrm{C}$ and $150^{\circ} \mathrm{C}$ (Fig. 1). However TRM acquisition experiments show that only $10 \%$ of the TRM is acquired below $150^{\circ} \mathrm{C}$. The fact that most of the TRM is acquired above the thermomagnetic Curie point, up to $300^{\circ} \mathrm{C}$ evidences that a minor population of titanomagnetite pseudosingle-domain grains carries the remanence (Fig. 1). The microdiorite is described in details in Gattacceca et al. (2007) and its physical properties are given in Table 1. The main magnetic mineral in the microdiorite is multidomain magnetite. As shown by the small standard deviations in Table 1, these two rocks have homogeneous magnetic properties at the $\sim 50 \mathrm{mg}$ scale. Therefore we can consider that for each rock all samples $(\sim 2 \mathrm{~g})$ used in the shock experiments have the same magnetic behaviour.

All magnetic measurements have been performed at CEREGE (Aix-en-Provence, France) with a $2 \mathrm{G}$ cryogenic magnetometer (remanent magnetization), Micromag Vibrating Sample Magnetometer (hysteresis properties) and a KLY2 Kappabridge (magnetic susceptibility) equipped with a CS2 furnace (thermomagnetic analyses). Thermal demagnetization and acquisition of artificial TRM were performed with a MMTD furnace.

\section{Shock waves induced by laser}

Pressure shock waves in the range of 1-5 GPa can be easily produced by laser induced plasma in the well-known water confined regime (Anderholm, 1970; Fabbro et al., 1989; Berthe et al., 1997). It consists in irradiating by a focused and pulsed (ns range) laser (GW.cm-2), the target material covered with few mm of water. The energy of the laser induces material ablation into a high-pressure plasma generating a compressive wave inside the target by the action/reaction principle. The expansion of the plasma, limited by the presence of the confining water, allows the generation of a pressure loading higher and longer than in the direct regime for same laser parameters (peak power density, pulse duration, wavelength). The maximum pressure generated by laser plasma in the water confinement regime is given 
by the following relation (Fabbro et al., 1989) validated experimentally (Fabbro 1989 et al.; Berthe 1997):

$$
P(G P a)=0.01 \sqrt{\frac{\alpha}{\alpha+3}} \sqrt{Z\left(g . c m^{-2} \cdot s^{-1}\right)} \sqrt{I_{0}\left(G W \cdot c m^{-2}\right)}
$$

where $\alpha$ is the fraction of the internal energy devoted to thermal energy (typically $\alpha=0.25$ ), $I_{0}$ is the incident power density and $\mathrm{Z}$ is the reduced shock impedance between the target and the confining water $\left(2 / Z=1 / Z_{\text {water }}+1 / Z_{\text {target }}\right)$. For basalt target in water confined regime, $Z_{\text {water }}=0.16510^{6} \mathrm{~g} \cdot \mathrm{cm}^{-2} \cdot \mathrm{s}^{-1}, Z_{\text {basalt }}=\rho_{0} C_{0}=Z_{\text {target }}=1.810^{-6} \mathrm{~g} \cdot \mathrm{cm}^{-2} \cdot \mathrm{s}^{-1}$ and $Z=3.0410^{5} \mathrm{~g} . \mathrm{cm}^{-2} \cdot \mathrm{s}^{-1}$. Equation (1) provides a link between the laser-matter interaction and the pressure loadings induced at the surface of the target material. Pressure increases with power density. At 1 and 2 GW. $\mathrm{cm}^{-2}$, pressure is 1.5 and $2.2 \mathrm{GPa}$ respectively.

The propagation of shock wave in the target basalt has been simulated using SHYLAC (Shock Hydrodynamic LAgrangian Code), a software developed at LCD (Laboratoire de Combustion et de Détonique, Poitiers, France). A good review on methods used in SHYLAC to simulate shock waves propagation in solids is presented also in Cottet and Boustie (1989), Antoun et al. (2003) and Zel'dovich and Raizer (1966). SHYLAC is a 1D finite difference code solving hydrodynamics conservative laws including a Mie-Grüneisen equation of state and a perfectly elasto-plastic constitutive law for metallic materials (von mises Criteria and hooke law). Main data required for SHYLAC simulations are: the pressure loading profile (obtained from equation (1) and Fabbro et al., 1989) and physical and mechanical material properties: density $\rho_{\mathrm{o}}$, yield strength $\mathrm{Y}_{0}$, shear modulus $\mathrm{G}$, Mie-Grüneisen coefficient $\gamma$, bulk sound velocity $\mathrm{C}_{0}$ and material constant $\mathrm{S}$. For the target basalt, these parameters are reported in Table 2. SHYLAC calculates the state of matter as a function of time and location in the target. In particular, pressure attenuation in the basalt can be computed (Fig. 2). The pressure decreases down to a depth for which it becomes constant at $0.6 \mathrm{GPa}$. This level corresponds to the pressure of the elastic wave propagating without attenuation (Berthe et al. 2007). This depth of elasto-plastic transition depends on the incident loading: it is $8.8 \mathrm{~mm}$ at $4 \mathrm{GW} . \mathrm{cm}^{-2}$ (3 GPa) against $0.86 \mathrm{~mm}$ at $0.16 \mathrm{GW} . \mathrm{cm}^{-2}$.

Clearly, the laser beam and high-pressure plasma induce a temperature increase in the material that is negligible in the present case. Indeed, the heated zone consists of a thin layer of only 10-20 $\mu \mathrm{m}$ (Peyre et al., 2007), to be compared to the thickness of sample (10 mm). Besides, the shock wave itself induces a temperature increase that is negligible (typically about a few ${ }^{\circ} \mathrm{C}$ ) for the pressures encountered in this work (e.g. Stöffler et al. 1991). 


\section{Experimental protocol}

The experimental protocol can be decomposed into two main steps: laser shock treatment in a controlled magnetic field followed by measurement of the remanent magnetization of the shocked sample. Oriented cylindrical samples (10 $\mathrm{mm}$ high, $9.5 \mathrm{~mm}$ in diameter, mean mass $2.14 \pm 0.05 \mathrm{~g}$ for the basalt and $1.98 \pm 0.01 \mathrm{~g}$ for the microdiorite) were subjected to laser shocks in the water-confined regime in a magnetic field controlled by three orthogonal pairs of Helmholtz coils (Fig. 3). The sample is held in place by a plastic device. There are no metallic parts inside the Helmholtz coils system. The experiments have been performed with a Ndglass laser at LCD (Laboratoire de Combustion et de Détonique, Poitiers, France). The pulse duration is $30 \mathrm{~ns}$, the maximum energy is $21.5 \mathrm{~J}$ and the spot diameter is $4.25 \mathrm{~mm}$ at the surface of the sample. This setting is described in more details in Gattacceca et al. (2006). For each laser shot, the pulse duration and shape and energy are recorded. The energy of the laser at the surface of the sample is adjusted by intercalating along the laser path calibrated neutral densities. Power densities used in this work are in the range $0.1-4 \mathrm{GW} . \mathrm{cm}^{-2}$.

In order to isolate the shock magnetization process without interference of the original magnetization of the basalt, the samples were fully demagnetized before the experiments and the residual remanent magnetization was measured. The basalt samples were demagnetized using thermal demagnetization at $290^{\circ} \mathrm{C}$ followed by alternating field (AF) demagnetization at $150 \mathrm{mT}$. The microdiorite samples were demagnetized using thermal demagnetization at $590^{\circ} \mathrm{C}$ followed by $\mathrm{AF}$ demagnetization at $150 \mathrm{mT}$. We checked on test samples of basalt and microdiorite that these thermal treatments had no effect on the intrinsic magnetic properties (hysteresis, magnetic susceptibility). The residual remanent magnetization is $5.20 \pm 2.1610^{-5}$ $\mathrm{Am}^{2} \mathrm{~kg}^{-1}$ for the basalt and $7.83 \pm 1.1310^{-5} \mathrm{Am}^{2} \mathrm{~kg}^{-1}$ for the microdiorite. The lower detection limit of the $2 \mathrm{G}$ DC SQUID magnetometer is about $10^{-11} \mathrm{Am}^{2}$, i.e. 4 orders of magnitude lower than these residual magnetization.

After the shock experiments, the remanent magnetization of the oriented samples was measured. If we suppose that the residual pre-shock magnetization is not affected by the shock (in view of its high coercivity), the vectorial difference between the post-shock magnetization and the pre-shock magnetization provides the SRM moment. The SRM was subsequently stepwise demagnetized with AF fields or thermal treatments.

\section{Results}


Although repeated shocks with the same intensity can create an increasing SRM (Nagata, 1971; Pohl, 1975), we performed a single shock experiment on each sample because the goal of this study is to model experimentally single natural impacts.

\subsection{Pressure and SRM homogeneity in the sample}

A first set of 12 basalt samples was submitted to shock of different intensity in a magnetic field of $200 \mu \mathrm{T}$ oriented parallel to the direction of shock. The intensities of the resulting SRM show that for an energy flux above $\sim 1 \mathrm{GWcm}^{-2}$ there is no significant increase of the SRM (Fig. 4). As a consequence, we used for all the other shock experiments a laser pulse with a constant energy flux of $\sim 1.9 \mathrm{GWcm}^{-2}$, which is enough to impart an almost complete SRM (an analogy for acquisition of TRM would be heating above the maximum blocking temperature). For an energy flux of $1.9 \mathrm{GWcm}^{-2}$ the pressure in the sample decays from $2 \mathrm{GPa}$ at the surface to $0.6 \mathrm{GPa}$ at the bottom of the sample (Fig. 2).

In order to study the possible decay of SRM with distance to the impact, we cut $1 \mathrm{~mm}$-thick parallelepipedic sub-samples (with mass $\sim 20-30 \mathrm{mg}$ ) from two shocked basalt samples using a wire saw with a wire diameter of $220 \mu \mathrm{m}$. For sub-samples located straight below the impact spot, the intensity of SRM is higher for the first upper mm and is fairly constant from 1 to $10 \mathrm{~mm}$ with a mean deviation of $5 \%$ around the mean intensity (Fig. 5). Referring to the pressure model of Fig. 2, this indicates that the SRM acquisition is approximately constant for pressures in the range $0.6-1 \mathrm{GPa}$, whereas it is $\sim 20 \%$ higher at $1.7 \mathrm{GPa}$. The same experiments for the microdiorite show a constant SRM from top to bottom of the shocked sample with a mean deviation of $10 \%$ around the mean SRM (Fig. 5), indicating almost complete shock magnetization even at the lower pressure suffered by the bottom of the sample ( $\sim 0.6 \mathrm{GPa}$ if we consider that the propagation of shock wave in the microdiorite is similar to the propagation in the basalt).

Unexpectedly, the SRM intensities of sub-samples taken directly straight below the laser spot or on the edges of the sample (more than $1 \mathrm{~mm}$ away from the loaded spot) show no significant difference (Fig. 5). The diameter of the loaded spot at the surface of the sample is $4.25 \mathrm{~mm}$, so that the volume located straight below the impact spot represents only $20 \%$ of the total volume of the sample. The fact that the whole volume of the samples is homogeneously affected by shock magnetization is probably linked to multiple 3D reflections of the elastic compression wave throughout the sample, which could result in a minimum peak pressure of $\sim 0.6 \mathrm{GPa}$ in the whole volume of the sample. Further work has been planned to clarify that point. 
In conclusion, with an energy flux of $1.9 \mathrm{GW} . \mathrm{cm}^{-2}$ the SRM acquisition is rather homogeneous in the cylindrical sample, as the whole volume of the sample seems to be affected by a minimum peak pressure of $0.6 \mathrm{GPa}$. This homogeneity justifies that the SRM intensity can be computed directly as the SRM moment measured on the bulk sample divided by the sample mass. With these shock settings, SRM in the microdiorite samples seems to have reached its maximum value whereas the SRM in the basalt samples is shy by at least $20 \%$ from its maximum value.

\subsection{SRM properties}

A second set of 54 basalt samples was submitted to shock with a mean energy flux of $1.89 \pm 0.16 \mathrm{GWcm}^{-2}$ in an ambient field varying in strength between $10 \mathrm{nT}$ and $2.5 \mathrm{mT}$, and varying in direction between $0^{\circ}$ and $90^{\circ}$ away from the direction of shock. For a given magnetic field, we do not observe a significantly lower SRM when the ambient field is perpendicular to the direction of propagation of shock than when it is parallel (Fig. 6). Nagata (1971) had observed a decrease of SRM by a factor of $\sim 0.75$ when the ambient field was perpendicular (for pressures up to $45 \mathrm{MPa}$ ). Our results indicate that this observation may be relevant only for low shock pressures $(<<1 \mathrm{GPa})$.

The SRM increases linearly with the ambient field in the $1 \mu \mathrm{T}-2500 \mu \mathrm{T}$ range (Fig. 7), confirming previous results (Nagata, 1971; Pohl, 1975) and extending them to higher and lower magnetic fields. It is noteworthy that within this field range, isothermal remanent magnetization is about one order of magnitude lower than SRM and does not contribute significantly to the magnetization of the shocked samples. Below $1 \mu \mathrm{T}$, the lack of linearity is likely attributable to poor control of the ambient field (see a similar discussion about TRM acquisition in $\mathrm{Yu}$ et al., 2007) and/or to an increasing relative contribution of a transient field possibly created by the laser shock itself (Srnka et al., 1979; Crawford and Schultz, 1988). Also, at low fields the expected SRM becomes lower than the residual magnetization before shock (Fig. 7) so that slight differences in orientation when measuring the residual magnetization and the post-shock magnetization vectors may result in a large error in the SRM computed as the difference between these two vectors. Moreover the subtraction does not take into account a possible shock demagnetization of the residual pre-shock remanence, even though the very high coercivity of the pre-shock remanence probably limits this effect.

Alternating field and thermal stepwise demagnetization show that samples have acquired a single component of magnetization during the shock (Fig. 8). SRM has a coercivity spectrum dominated by coercivities below $20 \mathrm{mT}$ with a median destructive field of $5 \mathrm{mT}$ compared to 
$11 \mathrm{mT}$ for TRM and $9 \mathrm{mT}$ for saturation isothermal remanent magnetization (sIRM) (Fig. 9). For a magnetizing field above $1 \mu \mathrm{T}$, the direction of the SRM is parallel to the direction of the applied field, with a mean angular departure of $3.8^{\circ}$ between the direction of impact and SRM, which is easily explained by the orientation errors during the shock experiments and magnetic measurements. For magnetizing field below $1 \mu \mathrm{T}$, the angular departure increases significantly for the above-mentioned reasons (poor field control and/or transient field).

In order to compare SRM acquisition with TRM acquisition, we conducted TRM acquisition experiments on a set of 5 other basalt samples, using fields between $10 \mu \mathrm{T}$ and $150 \mu \mathrm{T}$. The results are plotted in Fig. 7. The same set of experiments was conducted on 6 microdiorite samples. The data for the acquisition of SRM and TRM by the microdiorite are presented in Fig. 10. The AF demagnetization data of SRM, TRM and SIRM for the microdiorite are presented in Fig. 11.

For both the microdiorite and the basalt, the hysteresis properties and magnetic susceptibility show no variation with depth and are identical to the properties of unshocked samples, as expected in the pressure range used in this study $(<2 \mathrm{GPa})$, and in contrast with the permanent modification of magnetic properties observed for pressures $>10 \mathrm{GPa}$ (Gattacceca et al., 2007).

\section{Discussion}

The existing works about SRM acquisition (Nagata, 1971; Pohl et al., 1975; Nagata et al. 1983) allowed the main properties of SRM to be defined. SRM is parallel to the ambient magnetic field present at the time of shock, and its intensity is proportional to the strength of this field. The intensity of SRM increases linearly with pressure below $45 \mathrm{MPa}$ (Nagata, 1971; Nagata et al., 1983). For higher pressures, the intensity of SRM still increases with pressure, though with a decreasing rate. This was observed up to $1 \mathrm{GPa}(\mathrm{Pohl}, 1975)$ and it is probable that above a given pressure the intensity of SRM does not increase any more. Lastly, repeated shocks with the same intensity create higher and higher SRM. This effect is most dramatic at low pressures (Nagata, 1971) but remains visible for pressures up to at least $0.25 \mathrm{GPa}$ (Pohl, 1975).

The relative efficiency of SRM versus TRM acquisition is a valuable parameter for the interpretation of magnetic anomalies observed above impact basins. In the following, we define this efficiency (noted $\alpha$ ) as the ratio of SRM intensity to TRM intensity acquired in the same field. The absence of magnetic anomalies above extraterrestrial impact basins are generally interpreted as evidence that the dynamo had shut down at the time of impact (e.g. 
Acuña et al., 1999), but this cannot hold if $\alpha$ is $<<1$. In that case additional information about the magnetization in the rock melted during the impact (if they are preserved) is necessary. Data on SRM acquisition are scarce and no reliable data is available about the efficiency of SRM acquisition. $\alpha$ has been estimated between 1 and $10 \%$ for fine particle iron (Dickinson and Wasilewski, 2000), but Martelli and Newton (1977) have found, by impacting magnetitebearing basalts, that TRM and SRM acquisitions were equally efficient. Data from Pohl et al. (1975) on a titanomagnetite-bearing basalt indicate that $\alpha$ increases with pressure (up to 1 $\mathrm{GPa}$ ) and does not depend on the ambient field, at least between 100 and $700 \mu \mathrm{T}$.

The comparison between the SRM and TRM acquisition curves (Fig. 7 and 10) provides a precise estimate of the SRM efficiency $\alpha$ for a shock pressure of $\sim 0.6 \mathrm{GPa}$ (noted $\alpha_{0.6}$ ). The data show that $\alpha_{0.6}$ is independent of the magnetic field on the 1-1000 $\mu \mathrm{T}$ range. $\alpha_{0.6}$ values are 0.14 for the pseudosingle-domain titanomagnetite-bearing basalt, and 0.36 for the multidomain magnetite-bearing microdiorite. As discussed in $\S 5.1$, for the basalt $\alpha_{0.6}$ is shy by at least a factor 1.2 from the true $\alpha$ value that may be reached at higher pressure, whereas for the microdiorite $\alpha_{0.6}$ is probably close to the true $\alpha$ value. The differences between the $\alpha$ values for the microdiorite and the basalt indicate that $\alpha$ is sensitive to the intrinsic magnetic properties of the rock and that no general value can be proposed. For the basalt and the microdiorite, SRM has a coercivity spectrum shifted towards low coercivities with respect to TRM (Fig. 9 and 11). The median destructive field of SRM (resp. TRM) are $5 \mathrm{mT}$ (resp. $11 \mathrm{mT}$ ) for the basalt and $7 \mathrm{mT}$ (resp. $10 \mathrm{mT}$ ) for the microdiorite. This shift suggests that SRM will be more sensitive to viscous decay than TRM. As a consequence a SRM acquired in and around an impact basin may undergo more viscous relaxation than the surrounding TRM and may be relatively difficult to detect by now for impacts that are several billions years old (see Shahnas and Arkani-Hamed, 2007 for a quantitative estimate of TRM viscous demagnetization of the Martian crust for instance).

From the SRM and TRM alternating field demagnetization data, the efficiency of SRM versus TRM acquisition can be computed on different coercivity windows as the ratio of the SRM and TRM moments demagnetized over the same coercivity window, noted $\alpha^{\prime}$ (Fig. 12, following the concept of REM' introduced by Verrier and Rochette, 2002 and Gattacceca and Rochette, 2004). It clearly appears that the acquisition of SRM is more efficient at lower coercivities. The two rocks display contrasting behaviour: for the basalt $\alpha^{\prime}$ decreases quickly and is below 0.1 at $10 \mathrm{mT}$ whereas for the microdiorite $\alpha^{\prime}$ almost plateaus around 0.3 between $5 \mathrm{mT}$ and $40 \mathrm{mT}$. This conclusion is valid for the moderate shock pressures involved here (2 
GPa maximum) that do not result in "shock hardening" (shock-induced coercivity increase) as demonstrated in the higher pressure range (10 GPa) used in Gattacceca et al. (2007). When shock hardening is involved, SRM intensity and coercivity may become similar to the one of TRM (Gattacceca et al., 2007). In any case, even for the pressure range used in this work, it is noteworthy that SRM acquisition may be of the same order of magnitude as TRM acquisition for samples dominated by low-coercivity grains.

\section{Conclusion}

We have performed laser shock experiments on igneous rocks in controlled magnetic fields and studied the subsequent acquisition of remanent magnetization (SRM). Shock modeling indicates a pressure range of $0.6-1.5 \mathrm{GPa}$ for our experiments. Our results confirm that the SRM is parallel to the ambient magnetic field. SRM increase linearly with the ambient field in the $1 \mu \mathrm{T}-2500 \mu \mathrm{T}$ range, confirming previous results (Nagata, 1971; Pohl, 1975) and extending them to higher and lower magnetic fields. Contrary to previous studies (Nagata, 1971), we do not observe a lower SRM when the ambient field is perpendicular to the direction of propagation of shock than when it is parallel, which suggests that this observation may be relevant only for low shock pressures $(<<1 \mathrm{GPa})$. The coercivity spectrum of SRM is shifted towards lower values compared to the coercivity spectra of TRM and isothermal remanent magnetization.

Comparison of SRM and TRM acquired in the same magnetic field provides a precise value of the efficiency (noted $\alpha$ ) of SRM acquisition with respect to TRM acquisition, a parameter of interest for the understanding of the magnetic signatures of impact basins on extraterrestrial bodies. For the two studied lithologies, $\alpha$ is $\geq 17 \%$ for the basalt and is $36 \%$ for the microdiorite. $\alpha$ depends on the magnetic mineralogy and increases when coercivity decreases in agreement with a lower coercivity of SRM versus TRM. The range of observed $\alpha$ values shows that a significant remanent magnetization can be acquired by the crust during an hypervelocity impact on a planetary surface in the presence of an ambient field. As a consequence, this magnetizing mechanism must be considered when studying the magnetic signature of planetary surfaces submitted to impacts (on Mars, Earth, the Moon) or the paleomagnetism of meteorites that have almost all been shocked to pressures higher than a few GPa.

\section{Acknowledgements}


This manuscript benefited from careful and constructive reviews by Mike Fuller and an anonymous reviewer. We thank D. Hermitte (CEREGE) for sound speed measurements and A. Demant (Université Aix-Marseille 3) for the petrographic description of the target rocks. This work was funded by the French Agence Nationale de la Recherche.

\section{References}

Acuña, M.H., Connerney, J.E.P., Ness, N.F., Lin, R.P., Mitchell, D., Carlson, C.W., McFadden, J., Anderson, K.A., Rème, H., Mazelle, C., Vignes, D., Wasilewski, P., and Cloutier, P., 1999. Global distribution of crustal magnetization discovered by the Mars Global Surveyor MAG/ER experiment. Science 284, 790-793.

Anderholm, N.C., 1970. Laser-generated stresses Waves. Appl. Phys. Lett. 16, 113-115.

Antoun, T., Seaman, L., Curan, D. R., Kanel, G. I., Razorenov, S. V., Utkin, A. V. 2003. Spall fracture, Springer-Verlag Ed., New York, pp. 176-197.

Berthe, L., Fabbro, R., Peyre, P., Tollier, L., Bartnicki, E. 1997. Shock waves from a waterconfined laser-generated plasma. J. Appl. Phys. 82, 2826-2832.

Berthe, L., Bezaeva, N., Gattacceca, J., Boustie, M., Rochette, P., 2007. Mechanical characterization of basalt using shock wave induced by laser, Application to planetary hypervelocity impact effect. ICALEO 2007 proceedings, Orlando (USA).

Cisowski, S.M., Fuller, M., 1978. The effect of shock on the magnetism of terrestrial rocks. J. Geophys. Res. 83, 3441-3456.

Cottet, F., Boustie, M., 1989. Spallation study in aluminium targets using shock waves induced by laser irradiation at various pulse durations. J. Appl. Phys. 66, 4067-4073

Crawford, D.A., Schultz, P.H., 1988. Laboratory observations of impact-generated magnetic fields. Nature 336, 50-52.

Fabbro, R., Fournier, J., Ballard, P., Devaux, D., Virmont, J., 1989. Physical study of laserproduced plasma in confined geometry. J. Appl. Phys. 68, 775-784.

Gattacceca, J., Rochette, P., 2004. Toward a robust normalized magnetic paleointensity method applied to meteorites. Earth Planet. Sci. Lett. 227, 377-393.

Gattacceca, J., Boustie, M., Weiss, B.P., Rochette, P., Lima, E., Fong, L.E., Baudenbacher, F., 2006. Investigating impact demagnetization through laser impacts and SQUID microscopy. Geology 34, 333-336.

Gattacceca, J., Lamali, A., Rochette, P., Boustie, M., Berthe, L., 2007. The effects of explosive-driven shocks on the natural remanent magnetization and the magnetic properties of rocks. Phys. Earth Planet. Interiors 162, 85-98.

Halekas, J.S., Lin, R.P., Mitchell, D.L., 2003. Magnetic fields of lunar multi-ring impact basins. Meteor. Planet. Sci. 38, 565-578.

Hargraves, R.B., Perkins, W.E., 1969. Investigations of the effect of shock on natural remanent magnetism. J. Geophys. Res. 74, 2576-2589.

Hood, L., Richmond, N.C., Pierazzo, E., Rochette, P., 2003. Distribution of crustal magnetic fields on Mars: shock effects of basin-forming impacts. Geophys. Res. Lett. 30, doi: 10.1029/2002GL016657.

Martelli, G., Newton, G., 1977. Hypervelocity cratering and impact magnetisation of basalt. Nature 269, 478-480.

Louzada, K., Stewart, S.T., Weiss, B.P., 2005. The effect of shock on the magnetic properties of pyrrhotite, the Martian crust, and meteorites. Geophys. Res. Lett. 34, L05204, doi:10.1029/2006GL027685. 
Peyre, P., Carboni, C., Forget, P., Beranger, G., Lemaitre, C., Stuart, D., 2007. Influence of thermal and mechanical surface modifications induced by laser shock processing on the initiation of corrosion pits in 316L stainless steel, Journal of Material, in press.

Pohl, J., Bleil, U., Hornemann, U., 1975. Shock magnetization and demagnetization of basalt by transient stress up to 10 kbar. J. Geophysics, 41, 23-41.

Pilkington, M., Grieve, R.A.F., 1992. The geophysical signature of terrestrial impact craters. Rev. Geophysics 30, 161-181.

Nagata T., 1971. Introductory notes on shock remanent magnetization and shock demagnetization of igneous rocks. Pure Applied Geophys. 89, 159-177.

Nagata, T., Funaki, M., Dunn, J.R., 1983. Shock remanent magnetization of meteorites. Mem. National Institute Polar Res. 30, 435-446.

Shahnas, H., Arkani-Hamed, J., 2007. Viscous and impact demagnetization of Martian crust. J. Geophys. Res. 112, E02009, doi:10.1029/2005JE002424.

Srnka, L.J., Martelli, G., Newton, G., Cisowski, S.M., Fuller, M.D., Schaal, R.B., 1979. Magnetic field and shock effects and remanent magnetization in a hypervelocity impact experiment. Earth Planet. Sc. Lett. 42, 127-137.

Stöffler, D., Keil, K., and Scott, E.R.D., 1991. Shock metamorphism of ordinary chondrites. Geochim. Cosmochim. Acta, 55: 3845-3867.Verrier, V., Rochette, P., 2002. Estimating peak currents at ground lightning impacts using remanent magnetization. Geophys. Res. Lett. 29, doi:10.1029/2002GL015207.

Zel'dovich, Y.B., Raizer, Y. P., 1966. Physics of shock waves and high-temperature hydrodynamic phenomena, vol. 1, Academic Press, New York and London, pp. 1-96.

Yu Y. Tauxe L., Gee J.S., 2007. A linear field dependence of thermoremanece in low fields. Phys. Earth Planet. Interiors in press 


\section{Captions}

Figure 1 - Thermomagnetic curve for the basalt (susceptibility vs. temperature). Empty circles indicate the beginning of the heating curves. Heating $=$ thick line, cooling $=$ thin line. Progressive TRM acquisition is also plotted (dotted line, with standard deviation for the 3 measured samples).

Figure 2 - Peak pressure in the basalt sample as a function of depth for different energy densities applied by the laser at the sample surface. The pressure values are derived from the experimental calibration of Berthe et al. (2007).

Figure 3 - Sketch of the experimental setting used in this work.

Figure 4 - Shock remanent magnetization (SRM) acquired by the basalt samples in an ambient field of $200 \mu \mathrm{T}$ as a function of the energy flux applied by the laser pulse. Standard deviations are plotted when several samples were measured for the same energy flux.

Figure 5 - Shock remanent magnetization (SRM) of sub-samples located straight below the impact spot as a function of depth below the surface for a basalt sample (solid line) and a microdiorite sample (dashed line). The horizontal line is the mean value (with s.d. indicated by the grey band) of the sub-samples that are not located straight below the impact spot. The SRM are normalized to the remanence at saturation (Mrs) in order to take into account the natural variability in magnetic mineral content and properties at the scale of the $\sim 20 \mathrm{mg}$ sub-samples.

Figure 6 - Shock remanent magnetization (SRM) acquired in an ambient field of $100 \mu \mathrm{T}$ and a laser energy flux of $1.9 \mathrm{GW} . \mathrm{cm}^{-2}$ as a function of the angular deviation between the direction of shock and the direction of the ambient field. The dashed line is the linear best fit. Several samples have been measured for each orientation and the standard deviations are indicated by the vertical "error bars".

Figure 7 - TRM upon heating at $280^{\circ} \mathrm{C}$ (solid circles, solid line) and SRM upon laser shock with a mean energy density of $1.89 \mathrm{GWcm}^{-2}$ (open circles, dashed line) acquired by the 54 basalt samples as a function of the ambient magnetic field. Several samples have been studied for each field value and the standard deviations are indicated by the vertical "error bars". The residual remanent magnetization of the samples before the shock experiment is indicated by the thin horizontal line (with standard deviation indicated by the grey band).

Figure 8 - Orthogonal projection plots of stepwise demagnetization data of a basalt and a microdiorite cylindrical samples shocked with a laser energy density of $\sim 1.9 \mathrm{GW} . \mathrm{cm}^{-2}$ in a vertical magnetic field of $200 \mu \mathrm{T}$. Open and solid symbols are projections on vertical and 
horizontal planes, respectively. The post-shock magnetic moments are $5.8110^{-6} \mathrm{Am}^{2}$ for the basalt sample and $7.5610^{-7} \mathrm{Am}^{2}$ for the microdiorite sample.

Figure 9 - Alternating field demagnetization data of SRM acquired by the whole cylinder samples of basalt during the shock experiments. The data for saturation IRM (acquired in a $3 \mathrm{~T}$ field) and artificial TRM (acquired upon heating at $290{ }^{\circ} \mathrm{C}$ in a field of $100 \mu \mathrm{T}$ ) are given for comparison.

Figure 10 - TRM upon heating at $590^{\circ} \mathrm{C}$ (solid circles, solid line) and SRM upon laser shock with a mean energy density of $1.81 \pm 0.02 \mathrm{GWcm}^{-2}$ (open circles, dashed line) acquired by the 6 microdiorite samples as a function of the ambient magnetic field. When several samples have been studied for the same field value, the standard deviations are indicated by the vertical "error bars". The residual remanent magnetization of the samples before the shock experiment is indicated by the thin horizontal line (with standard deviation indicated by the grey band).

Figure 11 - Alternating field demagnetization data of SRM acquired by the acquired by the whole cylinder samples of microdiorite during the shock experiments. The data for saturation IRM and artificial TRM (acquired upon heating at $590{ }^{\circ} \mathrm{C}$ in a field of $100 \mu \mathrm{T}$ ) are given for comparison.

Figure 12 - Efficiency of SRM acquisition versus TRM acquisition in a given coercivity window $\left(\alpha^{\prime}\right)$ for the basalt (solid circles) and the microdiorite (empty circles). The alternating field value is the middle of the coercivity window of interest. The negative $\alpha^{\prime}$ values are attributable to measurement noise for high $\mathrm{AF}$ values. The total $\alpha$ values are indicated by the horizontal solid line (basalt) and the horizontal dotted line (microdiorite). 


\section{TABLES}

Table 1 - Magnetic and petrophysical properties of studied rocks

\begin{tabular}{|c|c|c|}
\hline & Basalt & Microdiorite \\
\hline Hysteresis properties & $(\mathrm{n}=12)$ & $(\mathrm{n}=12)$ \\
\hline $\operatorname{Mrs}\left(\mathrm{Am}^{2} \mathrm{~kg}^{-1}\right)$ & $1.59 \pm 0.3110^{-1}$ & $2.38 \pm 0.2010^{-2}$ \\
\hline $\operatorname{Ms}\left(\mathrm{Am}^{2} \mathrm{~kg}^{-1}\right)$ & $8.66 \pm 1.1910^{-1}$ & $1.28 \pm 0.1410^{-1}$ \\
\hline $\mathrm{Mr} / \mathrm{Ms}$ & $1.82 \pm 0.1610^{-1}$ & $1.39 \pm 0.0710^{-2}$ \\
\hline $\mathrm{Bc}(\mathrm{mT})$ & $6.30 \pm 0.88$ & $1.86 \pm 0.08$ \\
\hline $\operatorname{Bcr}(\mathrm{mT})$ & $14.4 \pm 1.8$ & $19.1 \pm 0.7$ \\
\hline $\mathrm{Bcr} / \mathrm{Bc}$ & $2.29 \pm 0.20$ & $10.3 \pm 0.4$ \\
\hline Main Curie temperature $\mathrm{s}\left({ }^{\circ} \mathrm{C}\right)$ & $60 / 150(n=4)$ & $575(n=3)$ \\
\hline Magnetic susceptibility $\left(\mathrm{m}^{3} \mathrm{~kg}^{-1}\right)$ & $1.61 \pm 0.2210^{-5}(\mathrm{n}=69)$ & $1.35 \pm 0.0710^{-5}(\mathrm{n}=28)$ \\
\hline Anisotropy of magnetic susceptibility (\%) & 2.4 & $4.0 \pm 0.8(n=3)$ \\
\hline Bulk density $\left(\mathrm{kg} \cdot \mathrm{m}^{-3}\right)$ & $3010 \pm 130(n=5)$ & 2730 \\
\hline Porosity $(\%)$ & 0.9 & 0 \\
\hline axial sound speed $\left(\mathrm{m} \cdot \mathrm{s}^{-1}\right)$ & 5960 & 5240 \\
\hline transverse sound speed $\left(\mathrm{m} . \mathrm{s}^{-1}\right)$ & 3380 & 3170 \\
\hline
\end{tabular}

When more than one sample has been measured, the number of measured samples is indicated. The anisotropy of magnetic susceptibility is given as the ratio (in \%) of maximum to minimum susceptibility. Bulk density was determined by measuring the mass and dimensions of rock cylinders. Porosity was computed using the grain density measured with a Quantachrome helium pycnometer. Sound speed was measured with a Panametrics Epoch III model 2300 ultrasonic flaw detection scope.

Table 2 : Mechanical properties of the basalt used in SHYLAC simulation.

\begin{tabular}{lc}
\hline Material & Basalt \\
\hline Density $\rho_{0}\left(\mathrm{~kg} \cdot \mathrm{m}^{-3}\right)$ & 3010 \\
Yield strength $\mathrm{Y}_{0}(\mathrm{GPa})^{*}$ & 0.200 \\
Shear Modulus G $(\mathrm{GPa})^{*}$ & 23.8 \\
Mie Grüseisen Coefficient $\gamma^{*}$ & 2 \\
Bulk sound velocity $\mathrm{C}_{0}\left(\mathrm{~m} \cdot \mathrm{s}^{-1}\right)$ & 5960 \\
Material constant s* & -1.5 \\
\hline
\end{tabular}

*: taken from Berthe et al. (2007) 


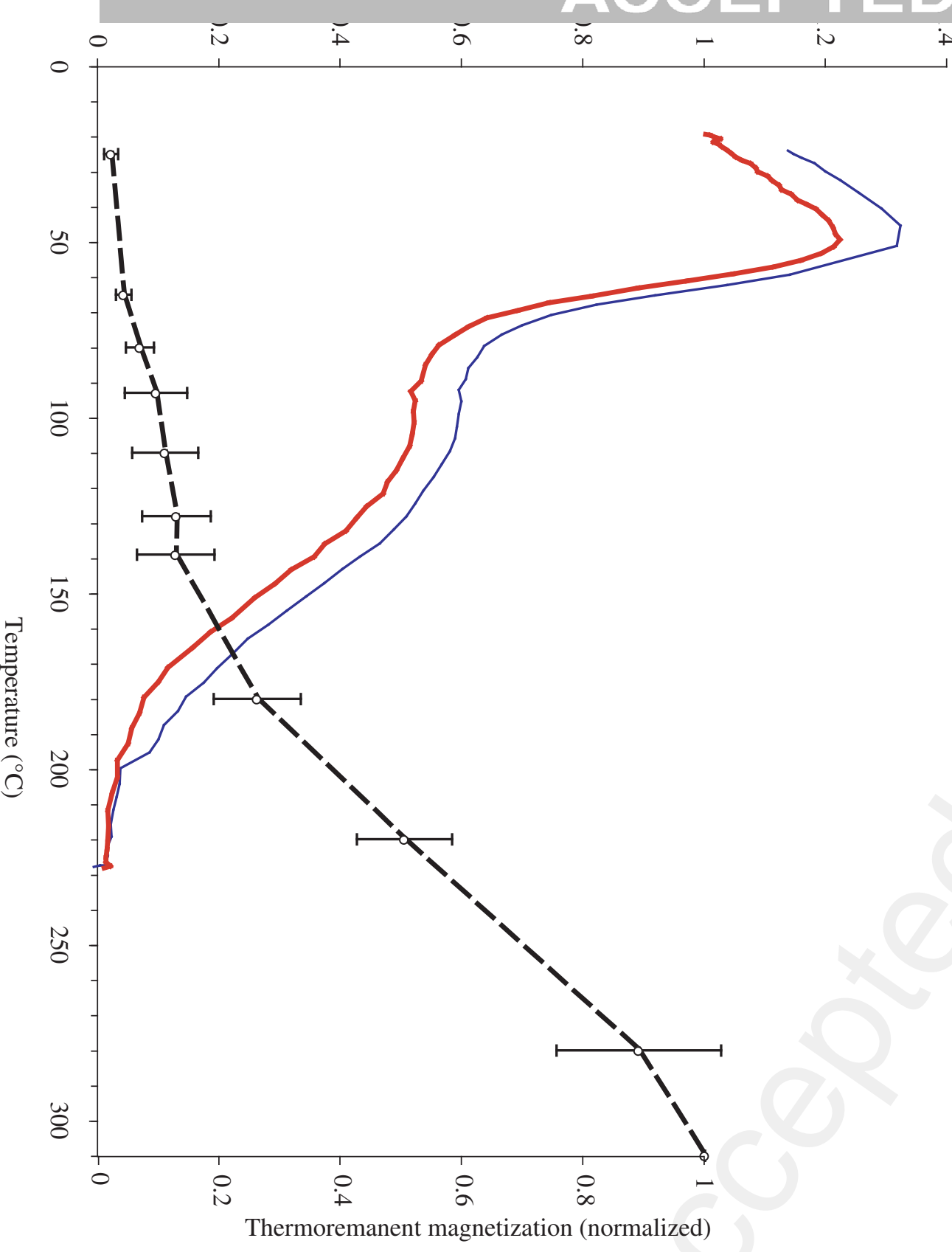




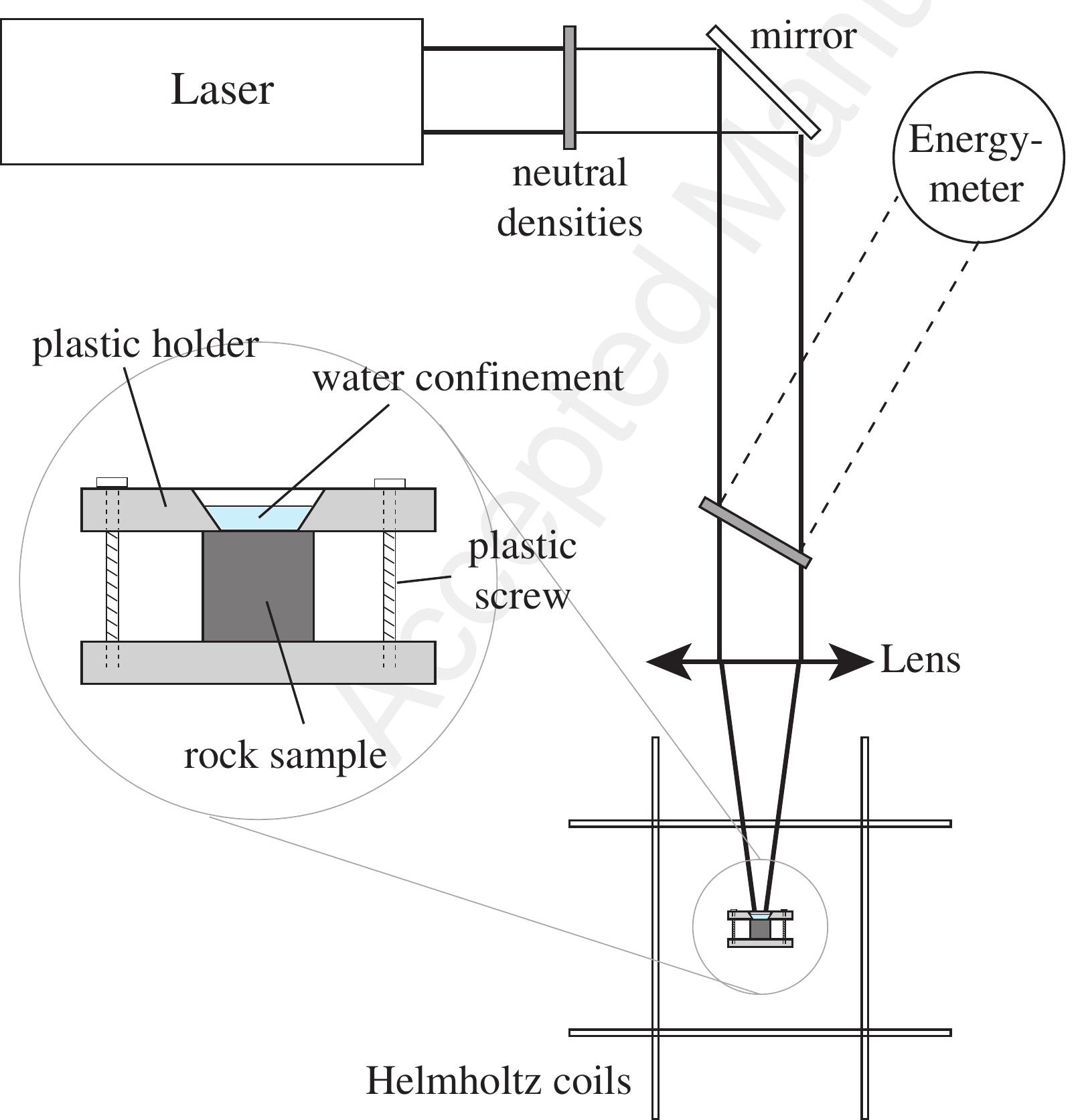




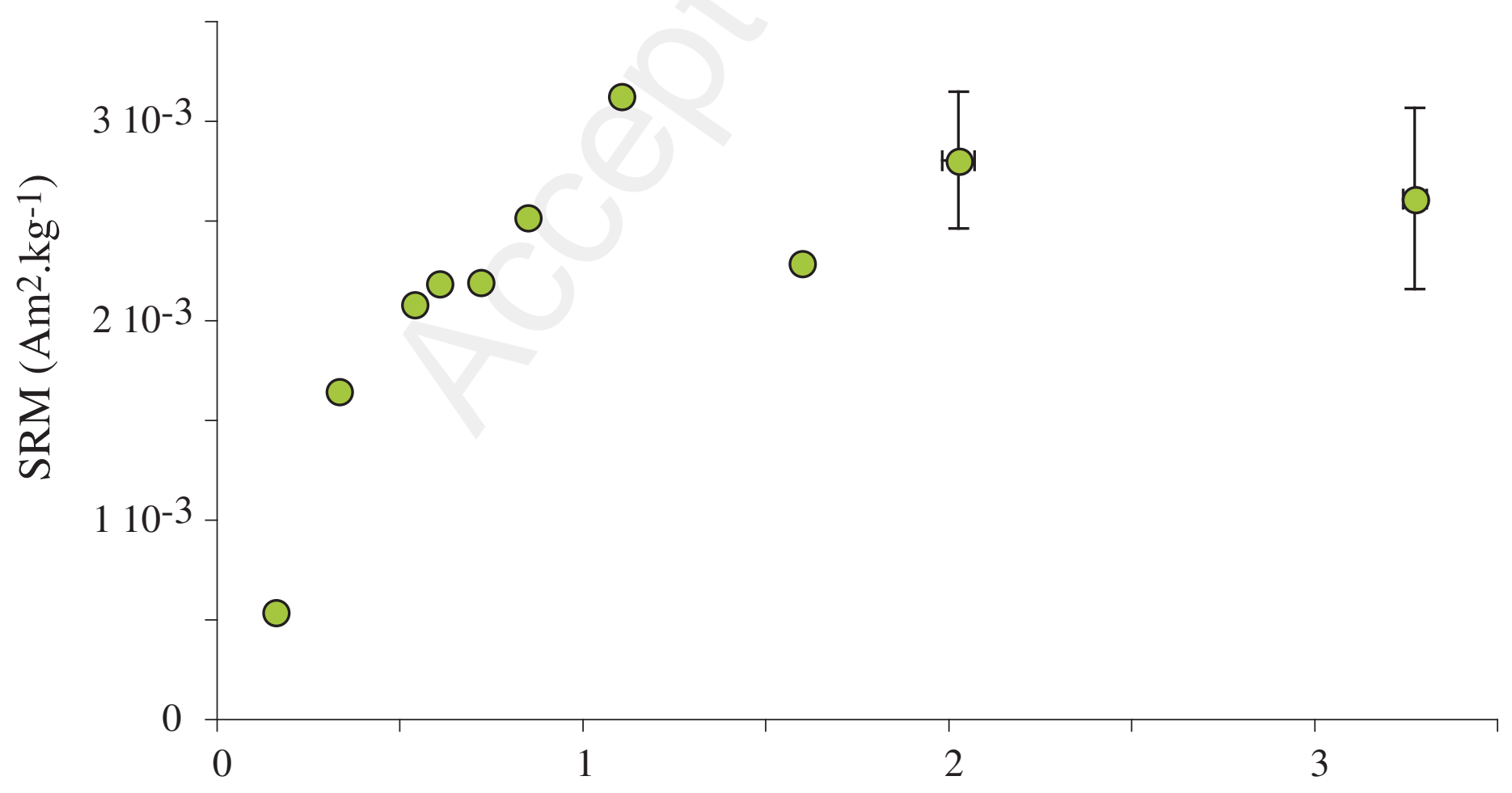

Energy flux (GW.cm-2) 


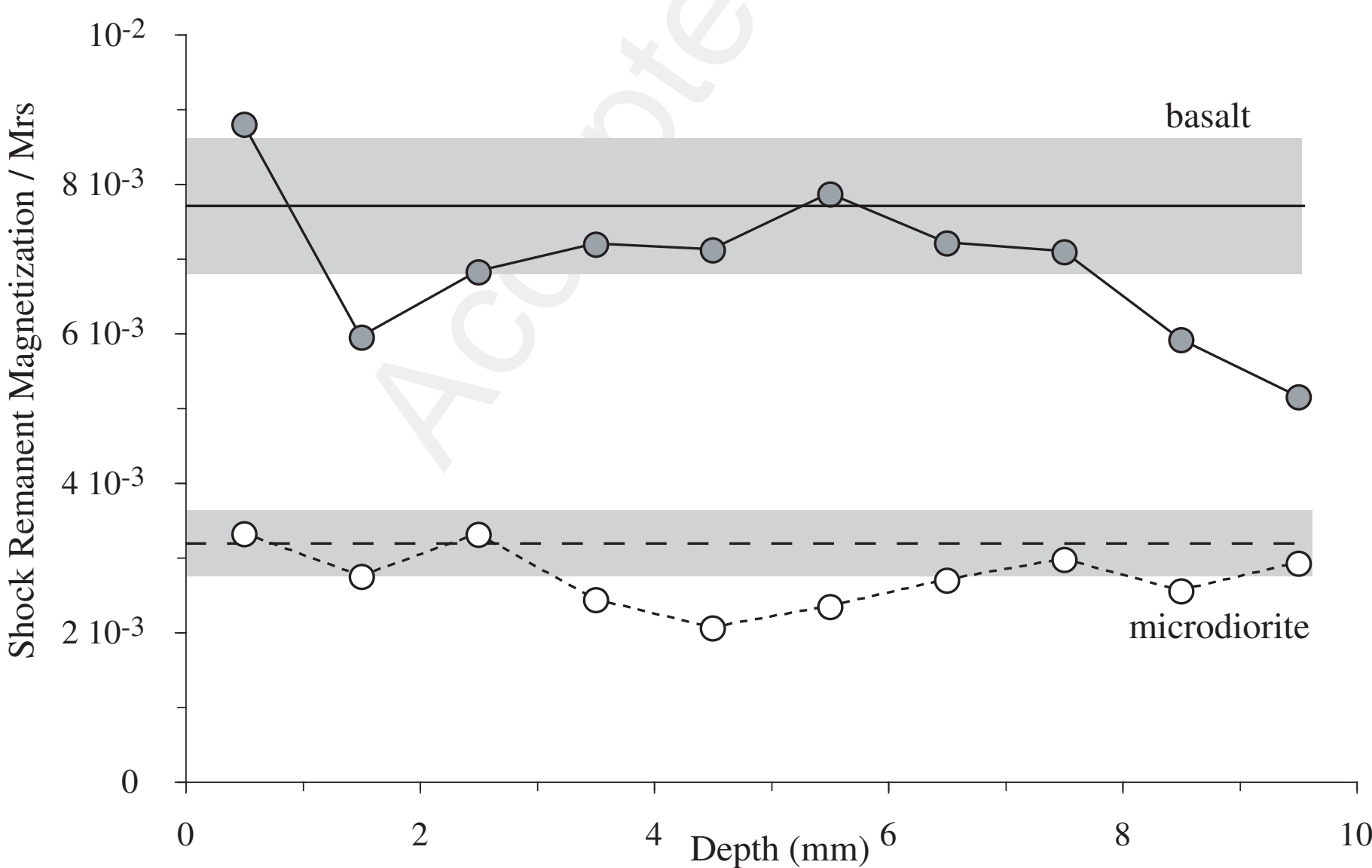




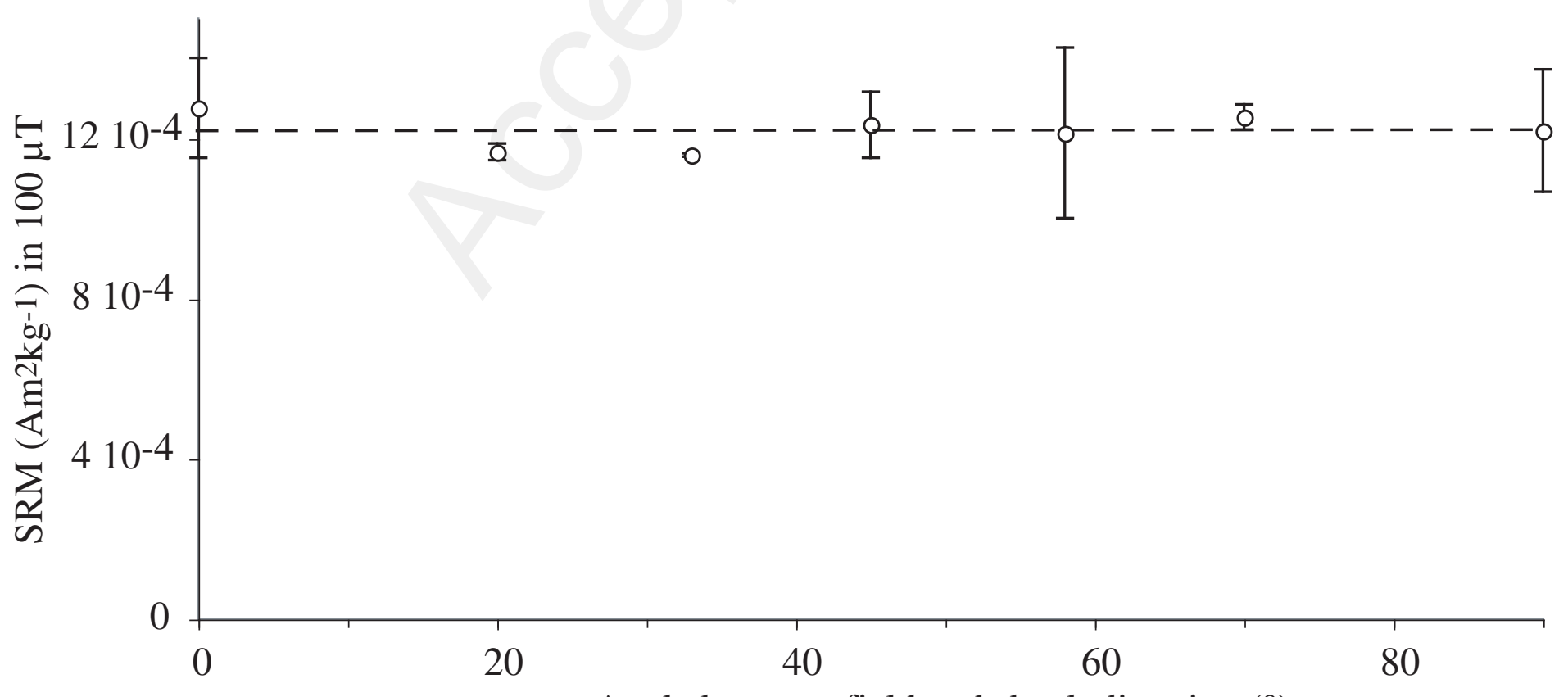

Angle between field and shock direction $\left(^{\circ}\right) \quad$ Page 21 of 27 


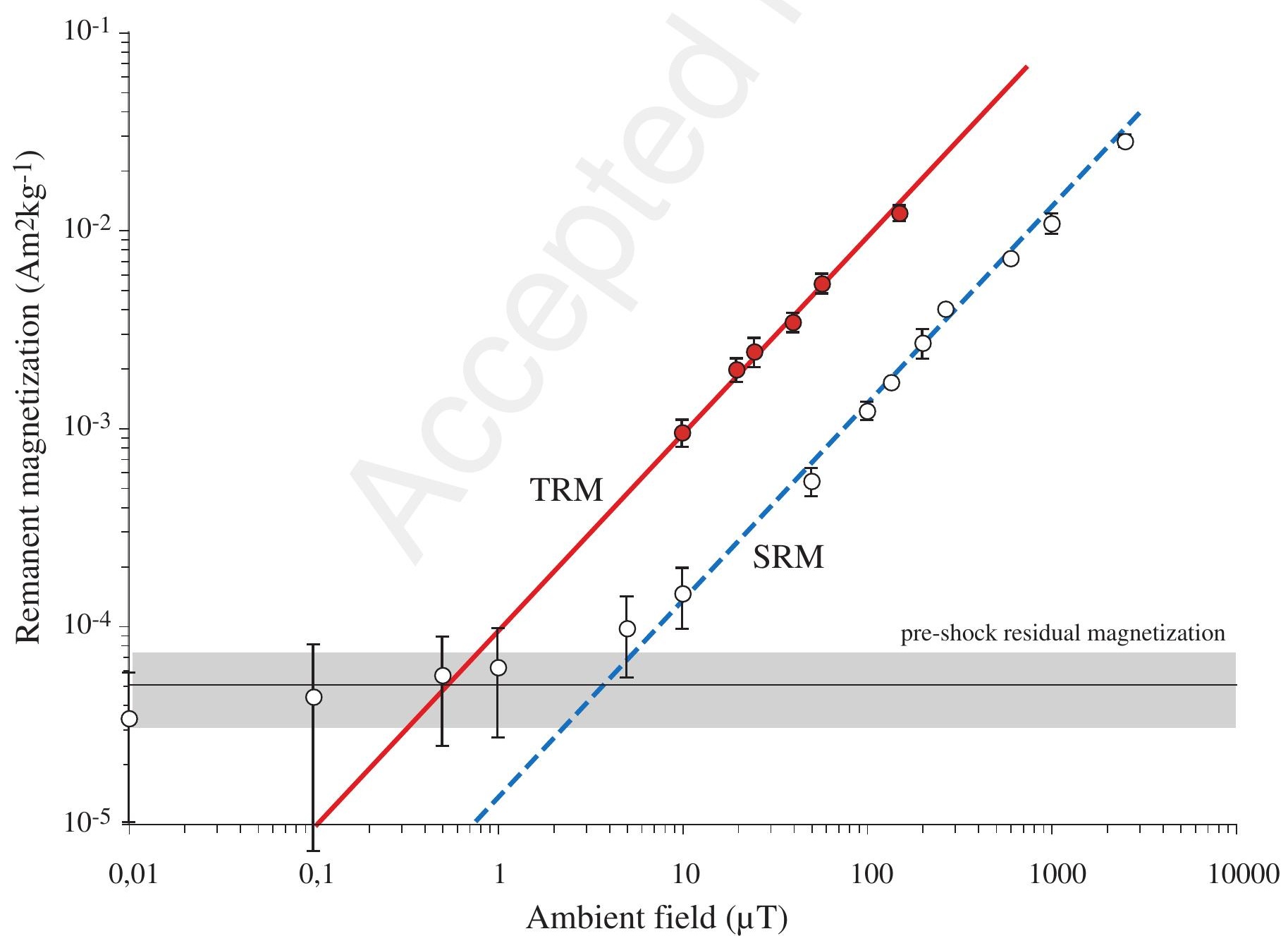

Page 22 of 27 
basalt

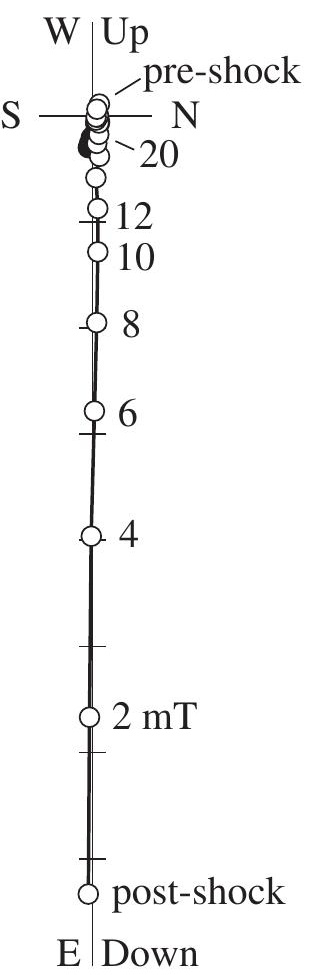

microdiorite

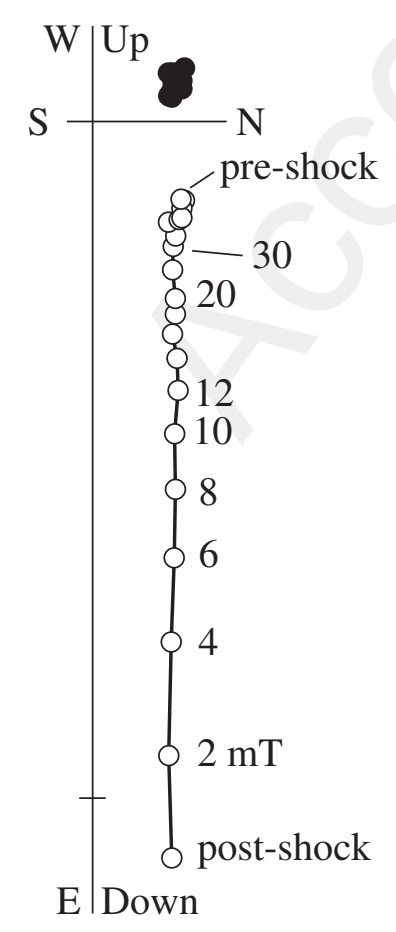




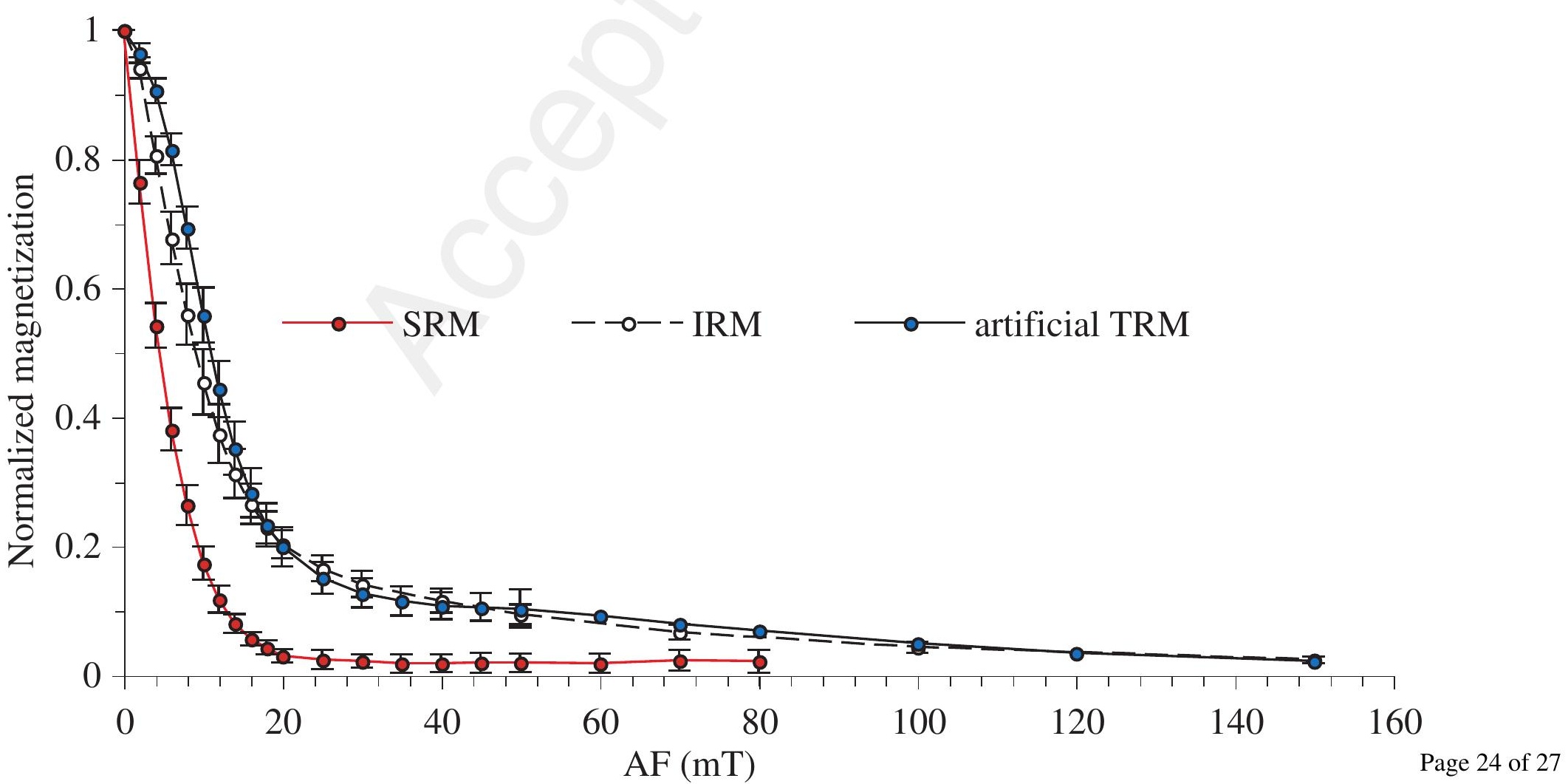




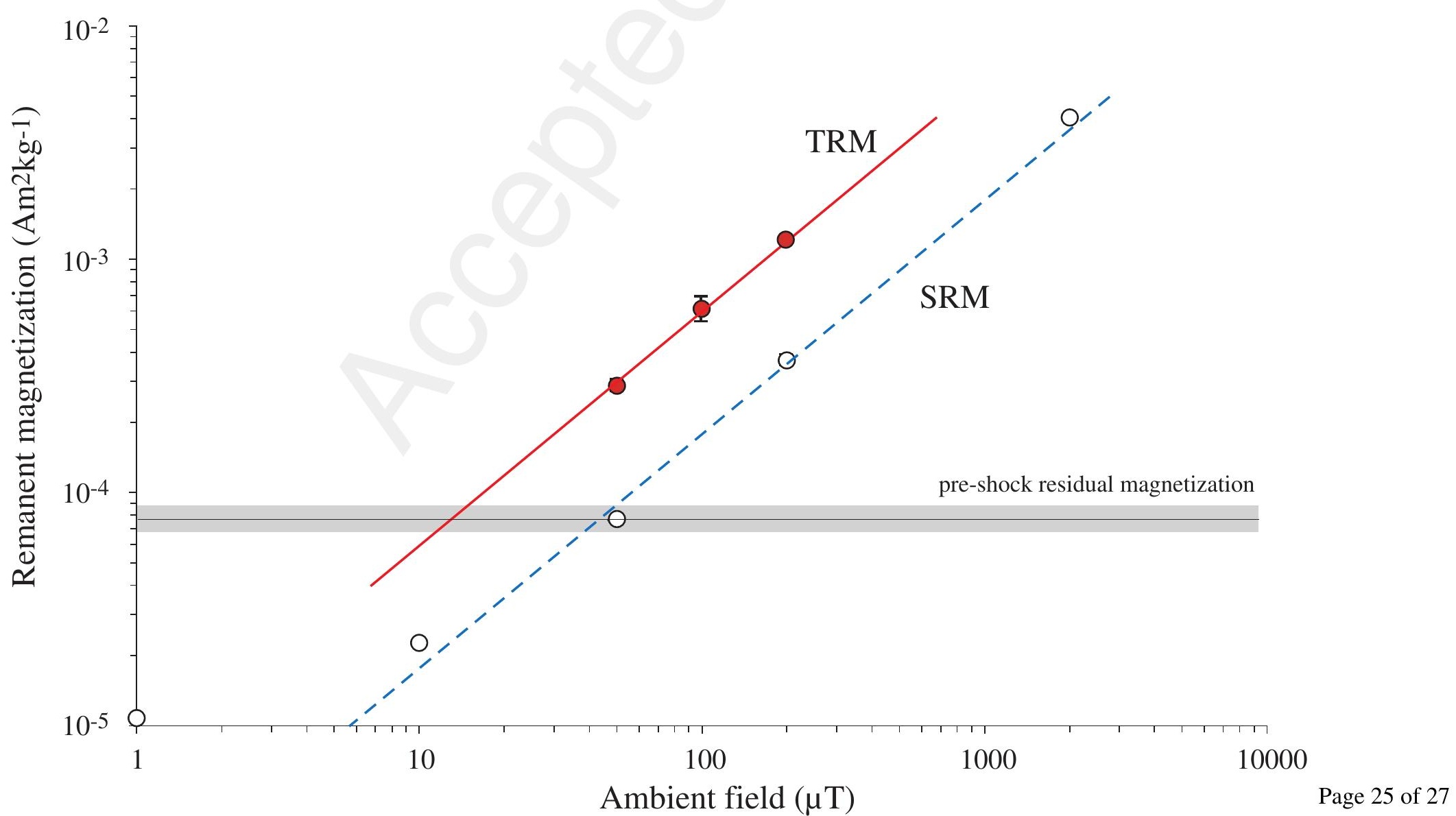




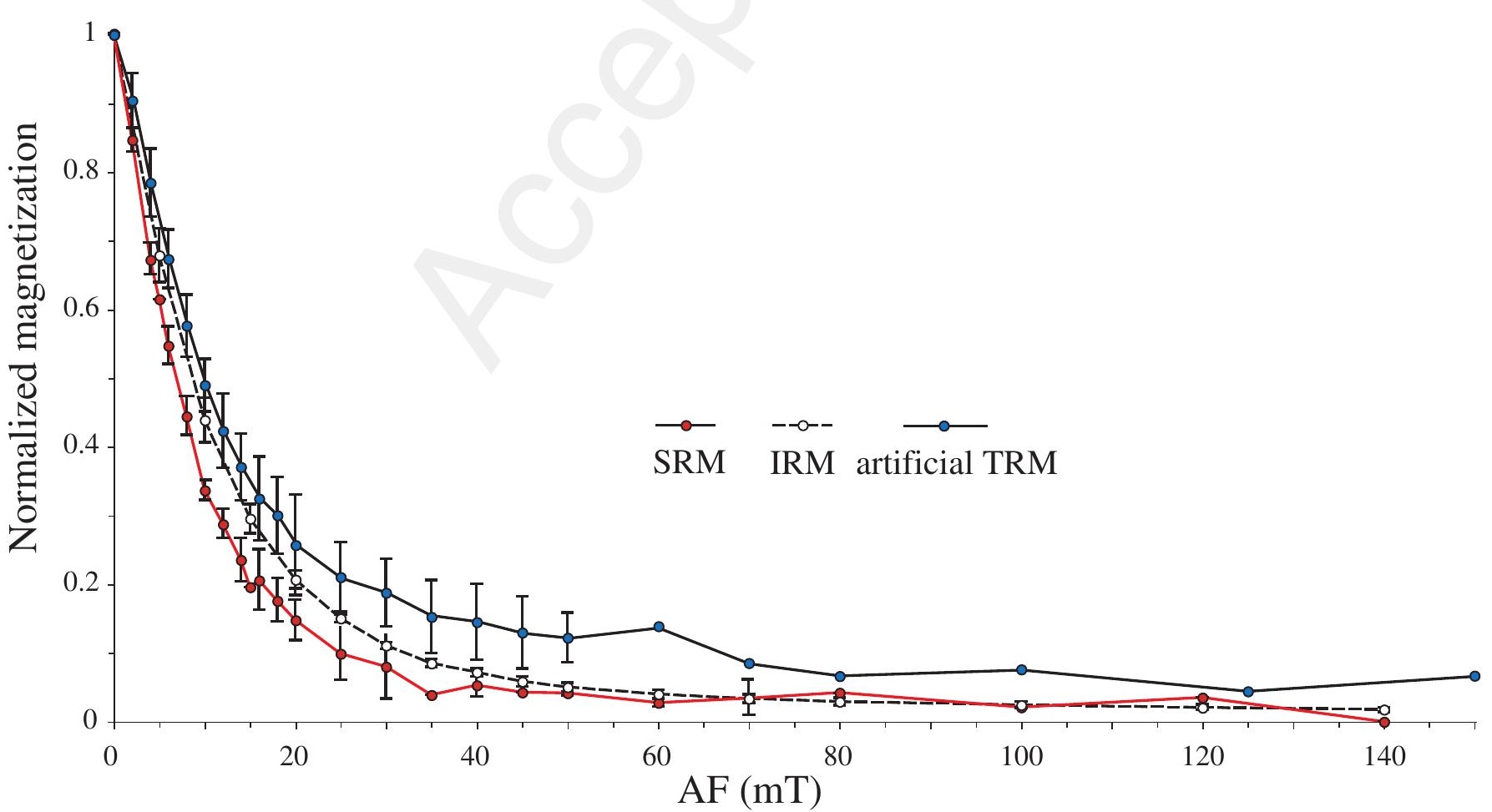


